\title{
An Overview of Leptin and the Th1/Th2 Balance
}

\author{
Buenaventura Brito Díaz1, Itahisa Marcelino Rodríguez¹, Delia Almeida González,2, \\ María del Cristo Rodríguez Pérez ${ }^{1}$, Antonio Cabrera de León ${ }^{1,3^{*}}$ \\ ${ }^{1}$ Research Unit University Hospital Nuestra Señora de Candelaria, Tenerife, Spain \\ ${ }^{2}$ Immunology Unit University Hospital Nuestra Señora de Candelaria, Tenerife, Spain \\ ${ }^{3}$ University of La Laguna, Tenerife, Spain \\ Email: acableo@gobiernodecanarias.org
}

Received 15 April 2014; revised 15 May 2014; accepted 22 May 2014

Copyright (C) 2014 by authors and Scientific Research Publishing Inc.

This work is licensed under the Creative Commons Attribution International License (CC BY). http://creativecommons.org/licenses/by/4.0/

(c) (i) Dpen Access

\begin{abstract}
Adipocytes produce hormones and adipokines, among others leptin, with metabolic and inflammatory responses. The role of leptin involves different subsets of the immune system. Low levels of serum leptin concentrations are associated with bacterial infections and produce susceptibility to allergic diseases and type Th2 autoimmune diseases. High levels of leptin are associated with Th1 autoimmune diseases via inflammatory responses. Leptin resistance, that happens in obesity, is characterized by the presence of high levels of serum leptin itself accompanied by a clinical situation of a Th2 response. There is a relationship between obesity, leptin resistance, altered immunity and sex hormones. Serum leptin concentration (Th1 response) in women is higher than in men maybe to achieve the balance Th1/Th2 because of the high level of estrogenic hormones (Th2 response) in women.
\end{abstract}

\section{Keywords}

Obesity, Leptin Resistance, Autoimmunity, Sex Hormones

\section{Introduction}

The current western lifestyle favors overnutrition and sedentarism. As a result, the prevalence of obesity in developed countries has risen steadily during the last 30 years. The prevalence of overweight is higher than $50 \%$ in men and 35\% in women; general obesity is around 30\% in both sexes [1].

Obesity is a chronic disease defined as an excessive growth of adipose tissue. Over the last several decades, obesity has become a public health problem due to its associated disorders and due to secretions of adipose tis-

*Corresponding author.

How to cite this paper: Brito Díaz, B., Marcelino Rodríguez, I., Almeida González, D., Rodríguez Pérez, M.C. and Cabrera de León, A. (2014) An Overview of Leptin and the Th1/Th2 Balance. Open Journal of Immunology, 4, 42-50. 
sue [2]. It can shorten life expectancy, and it is also a major factor in premature risk of many other diseases. It predisposes individuals to atherosclerosis [3], hypertension, diabetes mellitus [4] glomerulopathies, arthritis, neuropathologies [5] and cancer [6]. So that as the obesity "epidemic" spreads, it will lead to a reduction in life expectancies in developed countries [7]. Obesity influences the outcome of several immune mediated diseases.

In obesity adipocytes become hypertrophic, a change that reduces their oxidative capacity and renders them unable to store all the fat droplets that reach them via the bloodstream. Eventually this situation gives rise to fat deposits in cells of different organs that are not prepared for this function, and which are thus exposed to the effects of lipotoxicity [8]. However, it has been known since the 1990s that adipose tissue acts as an active endocrine organ that produces a number of hormones, pro-inflammatory cytokines, growth factors, complement system proteins and other molecules, which are together termed adipokines. Multiple roles in metabolic and inflammatory responses have been assigned to adipokines. Alterations in these substances production transform obesity into a condition characterized by chronic, low-intensity inflammation [9].

Obesity means not only an increase in the number and size of adipocytes but also an increase in adipose tissue infiltration by macrophages. Different types of cells in this tissue (pre-adipocytes, adipocytes, vascular stromal cells and macrophages) [10] present their own specific secretory and regulatory profiles. But obesity is also characterized by a large increase in perivisceral adipose tissue, a type of fat with a great capacity to secrete leptin, adiponectin, angiotensinogen, plasminogen activator inhibitor-1, resistin, IL-6 and more [2]. Leptin was the first adipokine to be discovered [11]; its functions are summarized in Figure 1.

- SUMMARIZING LEPTIN EVENTS-RELATED -

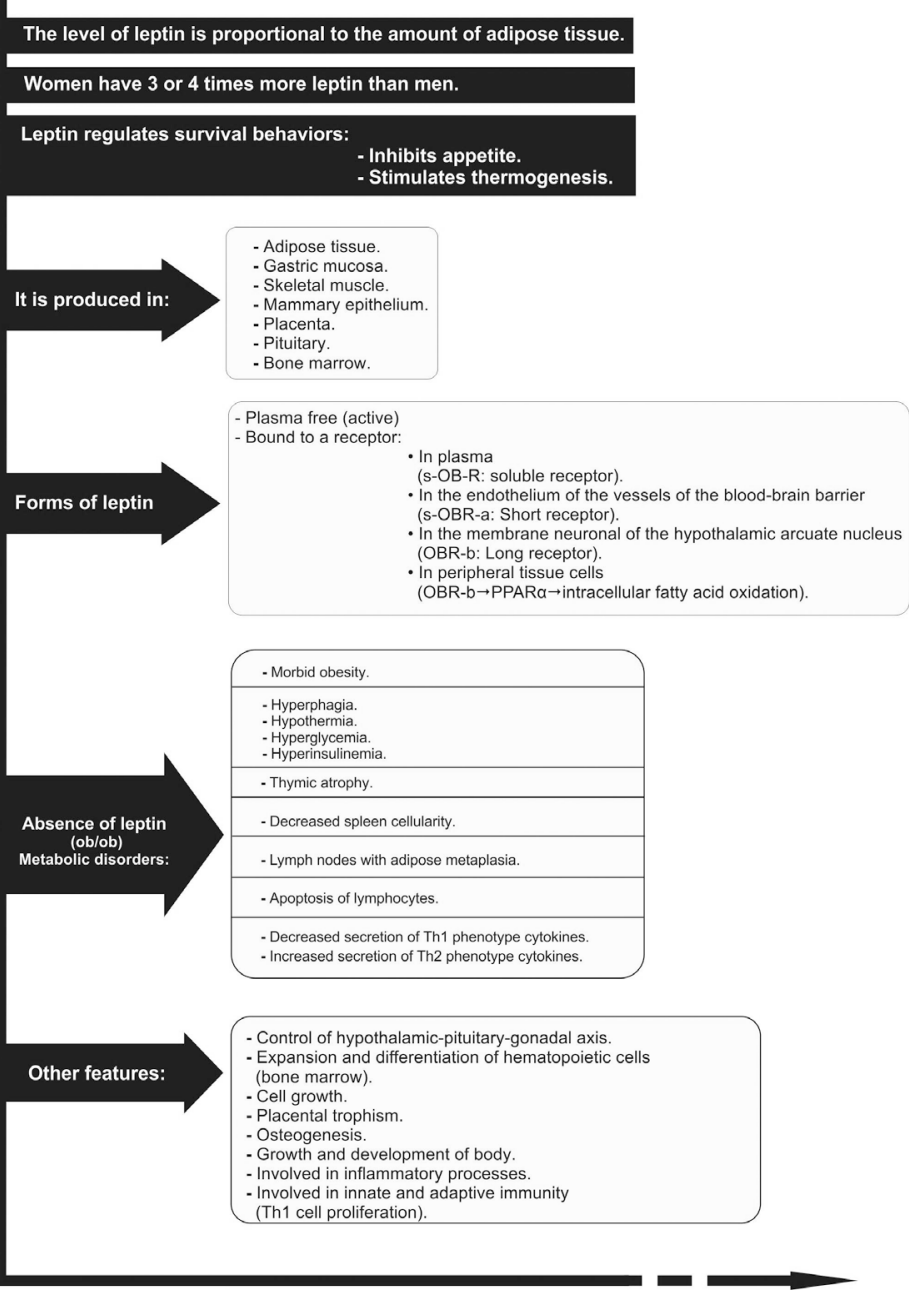

Figure 1. Production, forms and actions of leptin. 


\section{Obesity and Post Receptor Leptin Activity}

Leptin is involved in the hypothalamic-pituitary-gonadal axis. As a result its post-receptor action affects a number of physiological processes and pathological alterations in these processes [12].

Leptin deficiency in humans is associated with increased mortality from bacterial infections. Persons with obesity are more susceptible to infections in part owing because of leptin resistance, a phenomenon that arises in the blood brain barrier (BBB), in the hypothalamus and the peripheral non adipocyte cells. It is summarized in Figure 2. Leptin administration is only effective in individuals with genetic leptin deficiency, since they conserve substantial central and peripheral leptin receptor sensitivity. However, in extremely obese patients who are not leptin-deficient this treatment yields only small benefits because the high concentrations of circulating hormone mean that $\mathrm{Ob}-\mathrm{Rb}$ receptors are insensitive to leptin (leptin resistance). Nevertheless, these patients sometimes show some improvement: their appetite is reduced and there is partial improvement in their neuroendocrine, reproductive and autoimmune functioning [13].

Why leptin resistance occurs, have been attributed to some types of fat such as saturated fats [14]. However, hypolipidemic substances do not ameliorate resistance. In this sense, the cause of leptin resistance lies in inflammatory cytokines which can cause cell and tissue changes that alter Ob receptor physiology. We base this hypothesis on the following:

1) Leptin, is a cytokine whose receptors are quite similar to those of other cytokines and growth factors.

2) The fat stored in obesity, particularly abdominal fat, does not so much block receptors per se but rather generalizes the chronic inflammatory state and increases the production of cytokines. These molecules in their similarity to leptin, can interfere with leptin receptors.

3 ) It has been shown that a high-fat diet induces the expression of several pro-inflammatory cytokines (mainly TNF- $\alpha$, IL-1 $\beta$ and IL-6) in the hypothalamus. Fasting induces an anti-inflammatory effect on the neuroimmune system [15]. The increase in pro-inflammatory cytokines in the hypothalamus after a high-fat diet occurs together with an increase in SOCS3 and the appearance of insulin resistance in this brain structure.

4) Experimental studies confirmed that despite the appearance of leptin resistance in animal models, Ob-Rb receptor activation and the transduction signal via the janus kinase 2 (JAK2-STAT3) pathway remain intact. Reportedly, a member of the suppressor of cytokine signalling (SOCS) family acts as an inhibitor of the leptin transduction signal. The activity of SOCS3 increases 2-fold to 3-fold from the first day of chronic leptin infusion, and SOCS3 needs intact Ob-Rb and STAT3 pathways to act [16]. Moreover, chronic leptin infusion is accompanied by a decrease in plasma insulin concentration as a direct effect of leptin on pancreatic $\beta$ cells [17].

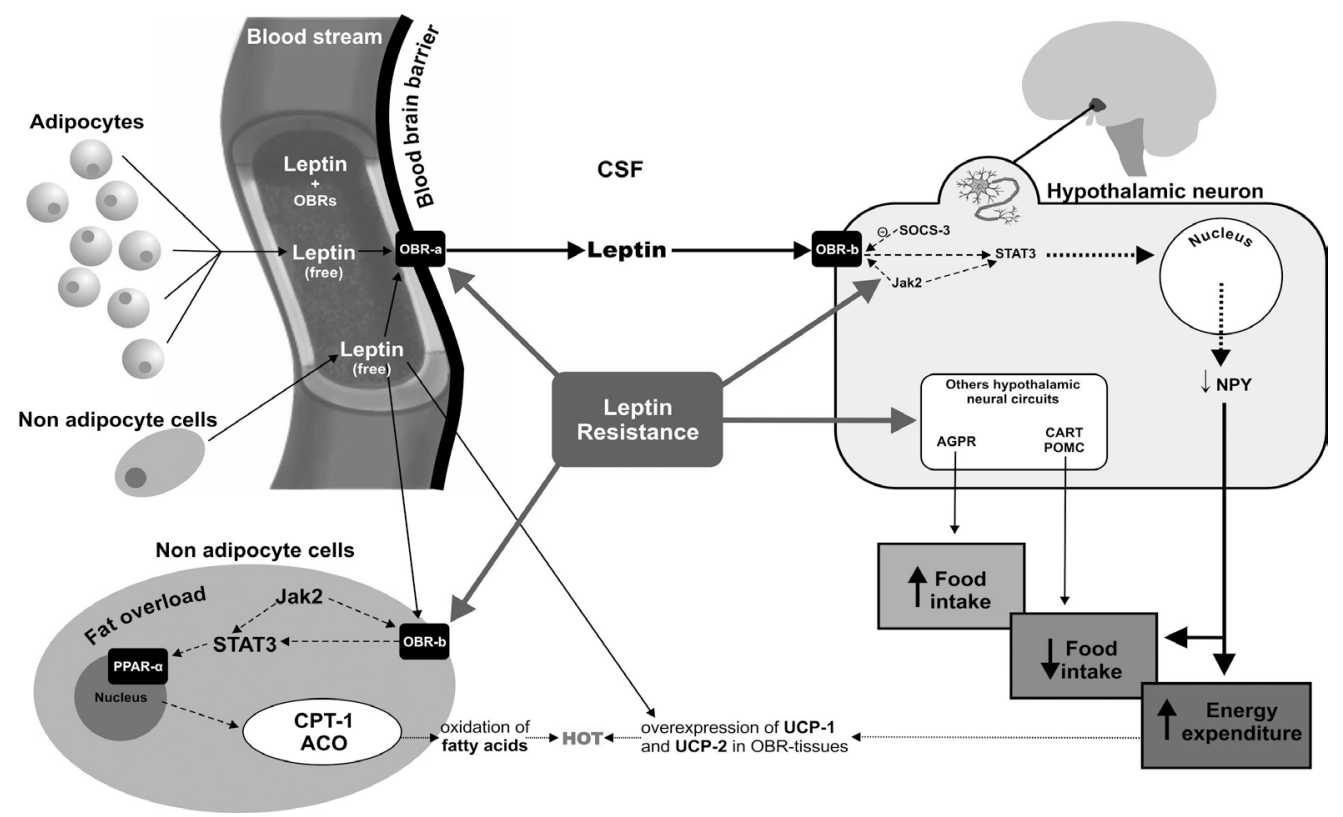

Figure 2. Leptin resistance arises in the blood brain barrier, in the hypothalamus and the peripheral non adipocyte cells. 
The identification of IL-27 and IL-27R has provided new insights for the biology of IL-6/IL-12 family cytokines. Some studies have revealed that IL-27R signaling influences a variety of immune cell types and can inhibit either Th1 or Th2 type responses, though elucidation of the Jak/STAT signaling pathways activated by IL-27R ligation has unveiled some of the molecular mechanisms used by cytokines to promote inflammation [18].

These findings suggest a central role for local inflammation in the pathophysiological mechanisms involved in leptin resistance [19].

\section{Immunity and Leptin}

The role of leptin involves different subsets of the immune system. The macrophages and monocytes are the best studied, but recently has been reported the involvement of other type of cells; such as neutrophils, mast cells, eosinophils, natural killer (NK); also, some T cells subsets, such a Th1, Th2, Th17 and B cells [20]. Leptin also inhibits CD4+ CD25+ Foxp3+ regulatory T cells (Treg), which are known to contribute significantly to the mechanism of peripheral immune tolerance [21].

Leptin participates in innate immunity by increasing the production of pro-inflammatory cytokines such as TNF- $\alpha$, IL-6 and IL-12 in monocytes and macrophages, and by increasing the production of proangiogenic factors and pro-inflammatory cytokines in human hepatic cells. In neutrophils it increases the expression of CD11b and its chemotaxis, and the production of oxygen-reactive species by these cells. It also regulates the differentiation, proliferation, activation and toxicity of natural killer cells. In acquired immunity, leptin induces the proliferation of T CD4+ and CD45RO+ cells in mixed cultures of lymphocytes. In addition, it increases the production of Th1-phenotype cytokines such as IL-2 and IFN- $\gamma$, while suppressing the production of Th2 cytokines such as IL-4. In mice, leptin reverses the immunosuppressive effects of acute starvation and produces a survival signal to thymocytes. It even protects the organism against starvation-induced lymphoid tissue atrophy in mice, increasing cellularity in the thymus of ob/ob mice. Thus, in addition to obesity, pro-inflammatory mediators appear to be the main factors able to increase leptin synthesis [22].

Although leptin pathway and its relationship with immunity is not the only actor; the modulatory roles of leptin are evident in the immune response, in energy homeostasis [23] and in hematopoiesis. In other words, leptin is necessary in the microenvironment as a factor in normal $\mathrm{T}$ cell development and angiogenesis [24].

Although rare, mutations in the human ob and db genes can occur [25], and can lead to massive obesity in individuals in whom reproductive functions are altered and immune abnormalities such as a reduction in $\mathrm{T}$ cells are present. These individuals also have a lower cellular immune response similar to that seen in ob/ob mice and they are predisposed to dying of infections from an early age [26].

\section{Leptin, Chronic Inflammation and Autoimmunity}

Specifically, increased plasma concentrations of leptin are associated with enhanced immune reactions in autoimmune processes via inflammatory responses [27]. In contrast, leptin deficiency is associated with a decrease in Th1 responses, and protects against autoimmune diseases because the deficiency favors the Th2 response. Leptin has even been related with increased sensitivity (induction and progression) to autoimmune diseases such as reumathoid arthritis (RA), systemic lupus erythematosus (SLE), multiple sclerosis (MS) or experimental autoimmune encephalomyelitis (EAE) [28]. In rheumatoid arthritis (RA) patients, fasting reduction of serum leptin levels produces a clinical improvement and a lower biological activity of the disease [29].

In experimental models of autoimmune diseases such as type 1 diabetes mellitus, leptin administration during the early phase of the disease accelerates the appearance and progression of the autoimmune process [30]. In contrast, studies in ob/ob mice indicate that these animals are resistant to EAE, a finding associated with a propensity toward Th2 responses, while leptin administration reversed EAE resistance. These animal models are also significantly resistant to other autoimmune diseases such as autoimmune colitis, autoimmune hepatitis and antigen-induced arthritis. Other studies have shown that leptin is involved in T cell-mediated hepatotoxicity in which IL-18 and TNF- $\alpha$ are produced. The production of these cytokines is reduced in ob/ob mice but recovers with leptin administration [28].

In human, women are 2 - 3 times higher in serum leptin levels than men adjusted for age and BMI, and are predisposed to autoimmune diseases such as SLE, MS and RA. Blocking the action of leptin delays the appearance and progression of EAE, which reflects an inverse correlation between serum leptin concentration and the number of CD4 (+) CD25+ regulatory T cells [22]. 
The pro-inflammatory cytokines TNF- $\alpha$, IFN- $\gamma$, IL-1, IL-6, and IL-12 play a very important role in the pathogenesis of autoimmune diseases in humans and animals, and neutralizing them in vivo often improves the clinical course and delays disease progression. Because of the substantial pro-inflammatory effect of leptin, a decrease in the activity of this hormone could raise the possibility of reducing chronic inflammation [31]. One advantageous approach may be to decrease leptin concentration by restricting caloric intake. Alternatively, diets rich in n-3 polyunsaturated fatty acids and low in saturated fatty acids may markedly lower leptin concentrations without affecting body fat. Clinical assays with food deprivation in patients with Th1 autoimmune disease and its effect on the inflammatory response have succeeded in reducing symptoms in some patients, delaying disease progression [32].

\section{Leptin and Th1/Th2 Balance}

In the metabolic-inflammatory process initiated by overweight and culminating in obesity status, leptin increases in parallel with fat stores, and its influence on the immune system leads to an increase in Th1 cells and a decrease in Th2 cells. At peak levels of manifestation and of Th1 cell influence, leptin, together with other adipokines, transforms obesity into an inflammatory state.

If the individual continues to store fat, leptin resistance becomes firmly established in both peripheral tissues and at the BBB. At that point the organism moves from a state of maximal post-receptor leptin activity to a marked decrease in activity, which favors the Th2 T cell phenotype. This transformation, along with the accompanying decline in Th1 cells, results in susceptibility to infections because of the weakening of the pro-inflammatory response against pathogens.

Thus, obesity can progress through different stages:

- Maximal Th1 activity $\equiv$ inflammatory state and susceptibility to type Th1 autoimmune diseases,

- Maximal Th2 activity $\equiv$ susceptibility to allergic diseases and type Th2 autoimmune diseases, which in turn gives way to:

- Minimal Th1 activity $\equiv$ susceptibility to infectious diseases.

This hormonal and metabolic deregulation conduces to an inflammatory environment, particularly in the most susceptible cells: neurons; which has consequences in the brain areas related with the regulation of food intake and energy expenditure.

Figure 3 illustrates one possible explanation of the pathological process involved in different stages of obesity by showing the parallels and interactions between the degree of post-receptor leptin activity and the plasma concentration of this hormone (as a reflection of adipose tissue stores), and by placing these changes in the context of a possible mechanism capable of modifying Th1/Th2 cell balance in men and women:

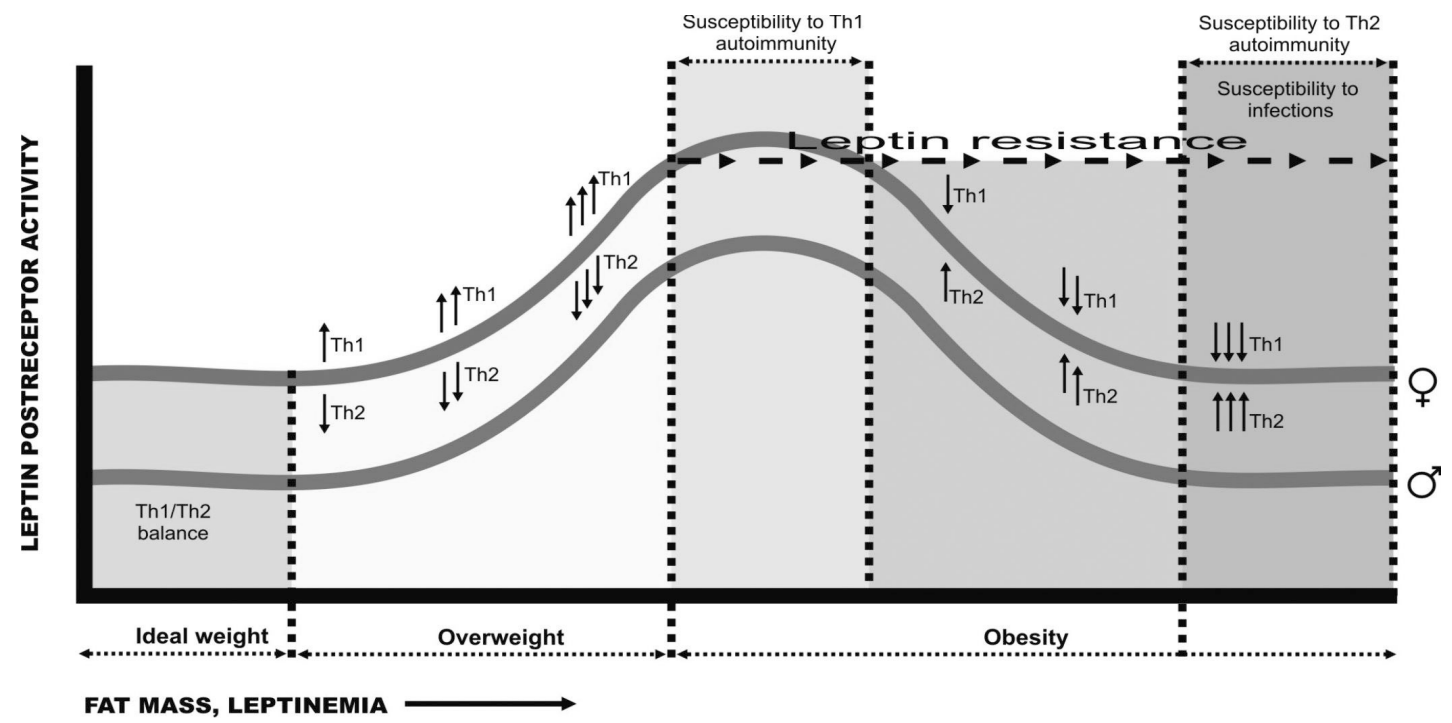

Figure 3. An explanation of the pathological process involved in different stages of obesity. Parallels and interactions between the degree of post-receptor leptin activity and the plasma concentration of this hormone in the context of Th1/Th2 cell balance. 
- The segments of the horizontal axis corresponding to overweight and the early stage of obesity denote a propensity toward the development of autoimmune processes initiated by a certain threshold level of obesity.

- The ascending parts of the Th1/Th2 activity curves denote the direct correlation between post-receptor activity, increasing fat stores and increasing leptin concentrations. In this part of the curves, Th1 cells are clearly predominant.

- Beyond the point at which leptin resistance appears, this correlation disappears or is even inverted, stimulation by Th1 cells diminishes and Th2 cells begin to predominate-a situation that leads to a propensity toward allergic diseases.

The steepness of the ascending and descending portions of the curves will depend on the individual's genetic susceptibility. Toward the right-hand portion of the diagram, corresponding to morbid obesity, the curve flattens when leptin enters the brain via routes other than the BBB. Because some residual post-receptor leptin activity remains, activity is never entirely abolished in individuals in whom there is no alteration in the genes that produce leptin or its receptor.

\section{Leptin and Sex Hormones}

A plausible interpretation of the fact that serum leptin concentration is 3-fold to 4-fold higher in women than in men is that women need higher leptin concentrations (Th1 response) to achieve Th1/Th2 balance because of the presence of estrogenic hormones (Th2 response). This protein is necessary to systemic functions derived from their role in the hypothalamic-pituitary-gonadal axis [33]. It could be that in women estrogens counteract the level of leptin owing to their own sex.

Improvements in nutritional status in the human population during recent decades have paralleled increases in the susceptibility to autoimmune diseases [34]. Given that leptin accelerates the appearance or progression of some autoimmune diseases (that involve a Th1 response) and that it also stimulates autoantibody secretion [35], it can be speculated that obesity is associated with an increase in antinuclear autoantibodies (ANA) but it is not the case [36]. One plausible explanation could be that in women with obesity leptin resistance would attenuate the Th1 response to this hormone and B cells would reduce their ANA production. As a result of the leptin-induced decrease in the Th1 response, the estrogen-induced Th2 response becomes predominant and the risk of Th2-profile diseases thus increases in women with obesity. In fact, obese women lose the strong correlation that exists in lean women between plasma leptin and sex hormones during the menstrual cycle [37].

In contrast, lean women have higher ANA titers because they have more Th1 response and their production is stimulated by leptin in an environment that presents no resistance to the actions of this hormone. Lean women of childbearing age would not be expected to develop severe hyperleptinemia because they have no excess adipose tissue and no leptin resistance. Although the influence of estrogenic hormones is intact, they maintain the balance between leptin activity (Th1) and estrogenic activity (Th2) thanks to physiological pseudo-hyperleptinemia compared to men of the same age and leanness. The greater physiological production of leptin may be responsible for the higher ANA titers and higher incidence type Th1 autoimmune diseases.

In women with obesity leptin increases and consequently its influence on Th1 cells, followed by the appearance of leptin resistance. Although plasma leptin concentrations continue to rise, post-receptor leptin activity eventually decays. As a result, despite hyperleptinemia, estrogen-derived Th2 activity predominates in women with obesity and the concentration of autoantibodies is lower, as is the incidence of Th1-influenced autoimmune diseases. An example of this is that during pregnancy, plasma estrogen concentrations are greatly increased but leptin concentrations remain unaffected. As a result, Th1-profile autoimmune diseases, like RA, often show clinical improvement during pregnancy, but worsen after childbirth with remission of the hyperestrogenic state. During pregnancy, however, diseases of Th2 predominance, like systemic lupus erythematous, worsen. Changes in the expression of autoimmune diseases that occur during these months are related to a reduction in the Th1/Th2 ratio [38].

In lean men the effects of leptin on the Th1 system are enhanced by the effect of androgens, although the lower level of physiological leptinemia in men prevents the effects of the pseudo-hyperleptinemia that occurs in women from appearing.

Some studies suggested that leptin concentration together with its association with insulin may be important in the well-known adverse effects of obesity on certain tumors, such as breast cancer. In addition to the participation of estrogens in explaining the effects of obesity on this type of cancer, leptin is a possible cause of estro- 
gen-dependent phenotypes because of its stimulatory effect on both normal and tumoral cell growth, along with its ability of increase angiogenesis. Leptin can also stimulate breast cancer by stimulating aromatase activity, which in turn promotes the production of estrogens from androstenedione in adipose tissue [39].

\section{Acknowledgements}

We thank Marta Rodríguez Pérez for her help in designing Figures.

\section{Financial Support}

Canarian Health Service.

\section{Conflicts of Interest}

None.

\section{References}

[1] Félix-Redondo, F.J., Grau, M., Baena-Díez, J.M., Dégano, I.R., de León, A.C., Guembe, M.J., et al. (2013) Prevalence of Obesity and Associated Cardiovascular Risk: The DARIOS Study. BMC Public Health, 13, 542. http://dx.doi.org/10.1186/1471-2458-13-542

[2] Leal Vde, O. and Mafra, D. (2013) Adipokines in Obesity. Clinica Chimica Acta, 419, 87-94.

[3] Samad, F. and Ruf, W. (2013) Inflammation, Obesity, and Thrombosis. Blood, 122, 3415-3422. http://dx.doi.org/10.1182/blood-2013-05-427708

[4] Colosia, A.D., Palencia, R. and Khan, S. (2013) Prevalence of Hypertension and Obesity in Patients with Type 2 Diabetes Mellitus in Observational Studies: A Systematic Literature Review. Diabetes, Metabolic Syndrome and Obesity: Targets and Therapy, 6, 327-338. http://dx.doi.org/10.2147/DMSO.S51325

[5] Lee, E.B. and Mattson, M.P. (2013) The Neuropathology of Obesity: Insights from Human Disease. Acta Neuropathologica, 127, 3-28. http://dx.doi.org/10.1007/s00401-013-1190-x

[6] De Pergola, G. and Silvestris, F. (2013) Obesity as a Major Risk Factor for Cancer. Journal of Obesity, 2013, 1-11. http://dx.doi.org/10.1155/2013/291546

[7] Olshansky, S.J., Passaro, D.J., Hershow, R.C., Layden, J., Carnes, B.A., Brody, J., et al. (2005) A Potential Decline in Life Expectancy in the United. New England Journal of Medicine, 352, 1138-1145. http://dx.doi.org/10.1056/NEJMsr043743

[8] Unger, R.H., Clark, G.O., Scherer, P.E. and Orci, L. (2010) Lipid Homeostasis, Lipotoxicity and the Metabolic Syndrome. Biochim Biophys Acta, 1801, 209-214. http://dx.doi.org/10.1016/j.bbalip.2009.10.006

[9] Wozniak, S.E., Gee, L.L., Wachtel, M.S. and Frezza, E.E. (2009) Adipose Tissue: The New Endocrine Organ? A Review Article. Digestive Diseases and Sciences, 54, 1847-1856.

[10] Itoh, M., Suganami, T., Hachiya, R. and Ogawa, Y. (2011) Adipose Tissue Remodeling as Homeostatic Inflammation. International Journal of Inflammation, 2011, 1-8. http://dx.doi.org/10.4061/2011/720926

[11] Wisse, B.E. (2004) The Inflammatory Syndrome: The Role of Adipose Tissue Cytokines in Metabolic Disorders Linked to Obesity. Journal of the American Society of Nephrology, 15, 2792-2800. http://dx.doi.org/10.1097/01.ASN.0000141966.69934.21

[12] Myers, M.G. Jr., Leibel, R.L., Seeley, R.J. and Schwartz, M.W. (2010) Obesity and Leptin Resistance: Distinguishing Cause from Effect. Trends in Endocrinology \& Metabolism, 21, 643-651. http://dx.doi.org/10.1016/j.tem.2010.08.002

[13] Farooqi, I.S., Matarese, G., Lord, G.M., Keogh, J.M., Lawrence, E., Agwu, C., et al. (2002) Beneficial Effects of Leptin on Obesity, T Cell Hyporesponsiveness, and Neuroendocrine/Metabolic Dysfunction of Human Congenital Leptin Deficiency. Journal of Clinical Investigation, 110, 1093-1103. http://dx.doi.org/10.1172/JCI0215693

[14] Banks, W.A., Coon, A.B., Robinson, S.M., Moinuddin, A., Shultz, J.M., Nakaoke, R., et al. (2004) Triglycerides Induce Leptin Resistance at the Blood-Brain Barrier. Diabetes, 53, 1253-1258. http://dx.doi.org/10.2337/diabetes.53.5.1253

[15] Lavin D.N., Joesting J.J. and Chiu G.S. (2011) Fasting Induces an Anti-Inflammatory Effect on the Neuroimmune System Which a High-Fat Diet Prevents. Obesity (Silver Spring), 19, 1586-1594. http://dx.doi.org/10.1038/oby.2011.73

[16] Wunderlich, C.M., Hövelmeyer, N. and Wunderlich, F.T. (2013) Mechanisms of Chronic JAK-STAT3-SOCS3 Signa- 
ling in Obesity. JAK-STAT, 2, Article ID: e23878. http://dx.doi.org/10.4161/jkst.23878

[17] Fujikawa, T., Chuang, J.C., Sakata, I., Ramadori, G. and Coppari, R. (2010) Leptin Therapy Improves Insulin-Deficient Type 1 Diabetes by CNS-Dependent Mechanisms in Mice. Proceedings of the National Academy of Sciences of the United States of America, 107, 17391-17396. http://dx.doi.org/10.1073/pnas.1008025107

[18] Villarino, A.V., Huang, E. and Hunter, C.A. (2004) Understanding the Pro- and Anti-Inflammatory Properties of IL-27. Journal of Immunology, 173, 715-720. http://dx.doi.org/10.4049/jimmunol.173.2.715

[19] Leon-Cabrera, S., Solís-Lozano, L., Suárez-Álvarez, K., González-Chávez, A., Béjar, Y.L., Robles-Díaz, G. and Escobedo, G. (2013) Hyperleptinemia Is Associated with Parameters of Low-Grade Systemic Inflammation and Metabolic Dysfunction in Obese Human Beings. Frontiers in Integrative Neuroscience, 7, 62. http://dx.doi.org/10.3389/fnint.2013.00062

[20] Guzmán-Flores, J.M. and López-Briones, S. (2012) Cells of Innate and Adaptive Immunity in Type 2 Diabetes and Obesity. Gaceta médica de México, 148, 381-389.

[21] Liu, Y., Yu, Y., Matarese, G. and La Cava, A. (2012) Cutting Edge: Fasting-Induced Hypoleptinemia Expands Functional Regulatory T Cells in Systemic Lupus Erythematosus. Journal of Immunology, 188, 2070-2073. http://dx.doi.org/10.4049/jimmunol.1102835

[22] Moraes-Vieira, P.M., Larocca, R.A., Bassi, E.J., Peron, J.P., Andrade-Oliveira, V., Wasinski, F., Araujo, R., Thornley, T., Quintana, F.J., Basso, A.S., Strom, T.B. and Câmara, N.O. (2013) Leptin Deficiency Impairs Maturation of Dendritic Cells and Enhances Induction of Regulatory T and Th17 Cells. European Journal of Immunology, 44, $194-806$.

[23] Morton, G.J., Cummings, D.E., Baskin, D.G., Barsh, G.S. and Schwartz, M.W. (2006) Central Nervous System Control of Food Intake and Body Weight. Nature, 443, 289-295. http://dx.doi.org/10.1038/nature05026

[24] Batra, A., Okur, B., Glauben, R., Erben, U., Ihbe, J., Stroh, T., Fedke, I., Chang, H.D., Zeitz, M. and Siegmund, B. (2010) Leptin: A Critical Regulator of CD4 ${ }^{+}$T-Cell Polarization in Vitro and in Vivo. Endocrinology, 151, 56-62. http://dx.doi.org/10.1210/en.2009-0565

[25] Clément, K., Vaisse, C., Lahlou, N., Cabrol, S., Pelloux, V., Cassuto, D., Gourmelen, M., Dina, C., Chambaz, J., Lacorte, J.M., Basdevant, A., Bougnères, P., Lebouc, Y., Froguel, P. and Guy-Grand, B. (1998) A Mutation in the Human Leptin Receptor Gene Causes Obesity and Pituitary Dysfunction. Nature, 392, 398-401. http://dx.doi.org/10.1038/32911

[26] Dubern, B. and Clement, K. (2012) Leptin and Leptin Receptor-Related Monogenic Obesity. Biochimie, 94, $2111-2115$. http://dx.doi.org/10.1016/j.biochi.2012.05.010

[27] Lam, Q.L. and Lu, L. (2007) Role of Leptin in Inmunity. Cellular \& Molecular Immunology, 4, 1-13.

[28] Cojocaru, M., Cojocaru, I.M., Siloşi, I. and Rogoz, S. (2013) Role of Leptin in Autoimmune Diseases. Maedica (Buchar), 8, 68-74.

[29] Palmer, G. and Gabay, C. (2003) A Role for Leptin in Rheumatic Diseases? Annals of the Rheumatic Diseases, 62, 913-915. http://dx.doi.org/10.1136/ard.62.10.913

[30] Sysi-Aho, M., Ermolov, A., Gopalacharyulu, P.V., et al. (2011) Metabolic Regulation in Progression to Autoimmune Diabetes. PLoS Computational Biology, 7, Article ID: e1002257. http://dx.doi.org/10.1371/journal.pcbi.1002257

[31] Falcón, G.J.J., Gazga, U.C., González, T.C. and Nájera, M.O. (2012) Regulación de la inmunidad por la leptina. Revista de Educación Bioquímica, 31, 92-99.

[32] Speakman, J.R. and Mitchell, S.E. (2011) Caloric Restriction. Molecular Aspects of Medicine, 32, $159-221$. http://dx.doi.org/10.1016/j.mam.2011.07.001

[33] Rogol, A.D. (2010) Sex Steroids, Growth Hormone, Leptin and the Pubertal Growth Spurt. Endocrine Development, 17, 77-85.

[34] Calder, P.C. (2013) Feeding the Immune System. Proceedings of the Nutrition Society, 72, 299-309. http://dx.doi.org/10.1017/S0029665113001286

[35] Ren, H., Zhao, H., Wang, T., Yang, Y., Han, Z., Liu, B., Wu, Z.D., Tao, J., Zhou, B., Zhang, L., Yang, R.C. and Han, Z.C. (2006) Leptin Enhances in Vitro Secretion of IgG Antiplatelet Antibodies by Splenocytes and Peripheral Blood Mononuclear Cells from Patients with Chronic Idiopathic Thrombocytopenic Purpura. Clinical Immunology, 120, 205-211. http://dx.doi.org/10.1016/j.clim.2006.04.573

[36] González, D.A., De León, A.C., Rodríguez Pérez, M.C., Coello, S.D., González Hernández, A., Fuentes, R.C., Jaime, A.A. and Diáz, B.B. (2008) Inverse Association between Obesity and Antinuclear Antibodies in Women. Journal of Rheumatology, 35, 2449-2451. http://dx.doi.org/10.3899/jrheum.080322

[37] Al-Harithy, R.N., Al-Doghaither, H. and Abualnaja, K. (2006) Correlation of Leptin and Sex Hormones with Endo- 
crine Changes in Healthy Saudi Women of Different Body Weights. Annals of Saudi Medicine, 26, 110-115.

[38] González, D.A., Díaz, B.B., del Cristo Rodríguez Péreza, M., Hernández, A.G., Chico, B.N. and de León, A.C. (2010) Sex Hormones and Autoimmunity. Immunology Letters, 133, 6-13. http://dx.doi.org/10.1016/j.imlet.2010.07.001

[39] Saxena, N.K. and Sharma, D. (2013) Multifaceted Leptin Network: The Molecular Connection between Obesity and Breast Cancer. Journal of Mammary Gland Biology and Neoplasia, 18, 309-320. http://dx.doi.org/10.1007/s10911-013-9308-2 